\section{Henry VIII's leg ulcers}

I read with interest the essay by Chalmers and Chaloner speculating on Henry VIII's leg ulcers and their possible impact on the course of history, but would take issue on the subject of aetiology. ${ }^{1}$

Lower-limb venous insufficiency severe enough to cause venous ulcers is much less common in men and particularly at Henry's relatively young age. Likewise, bilateral deep vein thromboses would be most unusual. In any case, venous ulcers, while always infected, are surprisingly painless unless complicated by cellulitis. The precise location of Henry's leg ulcers would aid diagnosis, but are demurely hidden in Hans Holbein's painting. Unless therein lies a subtle clue that he is actually wearing prescription Class 2 compression hosiery. It seems more likely that his patience was sorely tried by the pain incurred by traumatic ulceration, chronic infection, suppuration and 16th-century 'treatment' that would have been detrimental to almost any medical disorder. His diet and nutrition may have been excessive (BMI approx 50+) but at least poor healing due to vitamin deficiency could safely be ruled out.

It is a shame that for all Henry's reported interest in matters medical, he didn't have the foresight to create a 16thcentury prototype NICE.

\section{Peter Perkins}

Southbourne Surgery, 17 Beaufort Road, Bournemouth BH6 5BF

E-mail: peter.perkins@dorset.nhs.uk

\section{Competing interests}

None declared

\section{Reference}

1 Chalmers CR, Chaloner EJ. 500 years later: Henry VIII, leg ulcers and the course of history. J R Soc Med 2009;102:513-17

DOI 10.1258/jrsm.2010.100001

\section{Evaluating memory clinics}

Melis and colleagues ${ }^{1}$ argue for rigorous evaluation of memory clinics but at the same time admit that the need for service development is urgent, given the ageing of the population and the expected rise in the prevalence of dementia syndrome.

This dilemma is a common one, and leads to the use of 'best available' evidence to inform policy, rather than 'best quality'.

The National Dementia Strategy proposes a public education campaign about the early signs of dementia and asserts that general practice lacks the skills and confidence to undertake memory assessment. This risks weakening the gatekeeper function of general practitioners (GPs) and an unevaluated expansion of specialist services. The evaluation of such services that Melis and colleagues rightly desire cannot, in such circumstances, be about their effectiveness, since they are needed to manage the demand created by new policies. It could be an evaluation of their costs, and possibly their cost effectiveness.

Since one-quarter of the population aged 65 years and over have sufficient subjective memory impairment to cause them some concern, ${ }^{2}$ GPs could become very busy referring people with memory lapses to clinics that will in turn become increasingly crowded. Unfortunately subjective memory impairment correlates poorly with objective impairment, and is only a weak predictor of dementia; it is associated more strongly with depression. If those admitting to memory impairment are followed through with psychological testing, only one in five of those who subsequently develop dementia will be identified. ${ }^{3}$ The memory clinics could quickly fill up with the depressed. There is much that can be done for older people with depression, of course, but this would again require a re-engineering of a memory clinic model. Melis and colleagues have drawn an important issue to our attention.

\section{Steve lliffe ${ }^{1}$, Jill Manthorpe ${ }^{2}$}

1 University College London

${ }^{2}$ King's College London

Correspondence to: Steve lliffe

E-mail: s.iliffe@pcps.ucl.ac.uk

\section{Competing interests}

SI was a member of the external reference group for the National Dementia Strategy, and is currently a practice-based commissioner

\section{References}

1 Melis R, Meeuwsen E, Parker S, Olde Rikkert M. Are memory clinics effective? J $R$ Soc Med 2009;102:456-7

2 Jonker C, Geerlings M, Schmand B. Are memory complaints predictive for dementia? A review of clinical and population-based studies. Int I Geriatr Psychiatry 2000;15:983-91

3 Palmer K, Bäckman L, Winblad B, Fratiglioni L. Detection of Alzheimer's disease and dementia in the preclinical phase: population based cohort study. BMJ 2003;326:245

DOI 10.1258/jrsm.2010.090459

\section{All a matter of viewpoint}

I am afraid that the authors have fallen into a common pit for the unwary in diagnosing squint from a single image. ${ }^{1}$ Every orthoptist knows that in order to diagnose a squint it is necessary to begin with the eyes in primary gaze (straight to the front). Second, one needs to employ the cover test before proceeding to examine alignment in the other cardinal gaze positions. A corneal light reflex, if present, is the most useful marker for ocular alignment, but in portraits may be misleading.

Judging by the self-portrait of Dürer in their Figure 2, I contend that he is not displaying a squint at all, divergent or otherwise. Close scrutiny shows the corneal reflex in the right eye implies a convergent deviation, while the lack of visible lateral sclera a pseudo-divergent squint. In art, any apparent deviation of the eyes may be contrived with respect to the position of the observer. In this case, the sitter has his eyes to the right and fixed on an object more distant than the artist. This was historically a very common position adopted for portraiture, for a variety of artistic reasons.

For example, I enclose a photo similar to their portrait (Figure 1). This shows

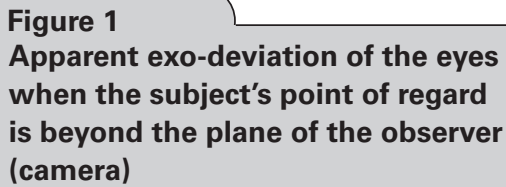

Figure 1

Apparent exo-deviation of the eyes when the subject's point of regard is beyond the plane of the observer (camera)

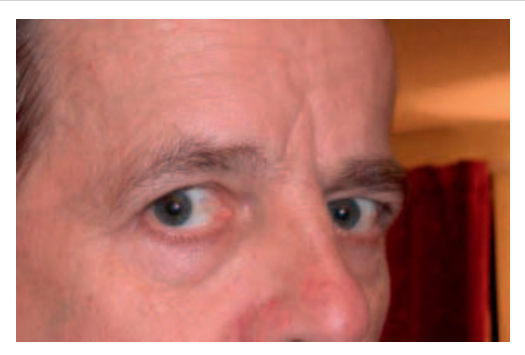


someone gazing to their right and beyond the camera. Despite appearances, the sitter has no squint and excellent stereoacuity - as befits a practising strabismologist!

\section{Rob Doran}

Consultant Ophthalmic Surgeon, Victoria Eye Unit, County Hospital, Hereford HR1 2ER, UK E-mail: rob.doran@hhtr.nhs.uk

Competing interests

None declared

\section{Reference}

1 Aronson J, Ramachandran M. The diagnosis of art: Dürer's squint - and Shakespeare's? J R Soc Med 2009;102:391-3

DOI 10.1258/jrsm.2010.100038 